
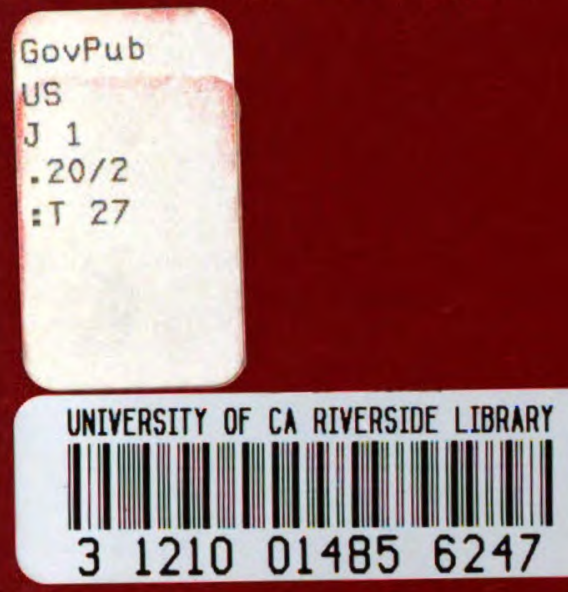

$+1$

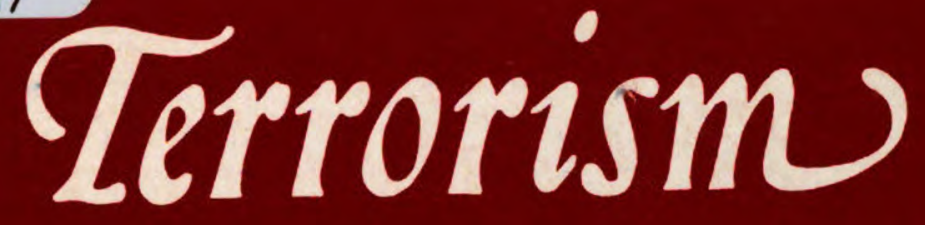

\title{
A Selected Bibliography
}

National Institute of Law Enforcement and Criminal Justice Law Enforcement Assistance Administration

United States Department of Justice 